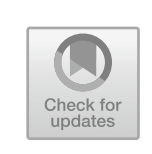

\title{
Implementing Quantum Management: The RenDanHeyi/Zero Distance Business Model
}

Haier, China was the first large, global company in the world to implement Quantum Management Theory, in its own RenDanHeyi Management Model, and its undoubted success in doing so has proven that the theory can work in practice, in a real company. Other companies, discussed later in this book, have now followed Haier's pioneering example and adopted Quantum Management as implemented by their own adaptations of the RenDanHeyi model. Because no theory has much value unless it can be implemented in practice and produce real results, it is important we look closely here at the origin and nature of RenDanHey as an example of Quantum Management in practice, and view it as a generic organizational model drawing from Quantum Management theory that can be adapted for use in many spheres. Indeed, my faith that implementing RenDanbeyi is a positive and meaningful way of changing the world for the better, is what this book is about.

Haier is the world's largest supplier of domestic appliances and a leading actor in the Internet of Things (IoT) sector, directly employing more than 75,000 people in China alone, and another 27,000 globally, but today the company is better known for the revolutionary RenDanHeyi Management Model than for its appliances. Indeed, because of the almost infinite expansion allowed by that model, Haier has now moved well beyond simply manufacturing appliances into products and services such as clothing, food, agriculture, biotechnology and health

D. Zohar, Zero Distance, https://doi.org/10.1007/978-981-16-7849-3_5 
care, and this expansion is continuing. While traditionally managed Taylorian companies have realized an annual growth of $1.1 \%$ during recent years, since fully implementing RenDanHeyi in 2012, Haier has realized a $23 \%$ annual growth. And while, with the exception of the big e-commerce companies, nearly every large retail company in the world suffered major losses and contraction during and as a result of the Covid-19 crisis, the unique features of its RenDanHeyi model saw Haier back in full production by mid-February 2020, and achieving growth as the crisis played out while others were contracting.

Haier's CEO, Zhang Ruimin, who conceived the RenDanHeyi model-and who is cited by Corporate Rebels as "arguably the leading management strategist of modern times"-claims it has universal application in any industry (see Chapter 15, which explores in more detail how Haier itself implements RenDanHeyi). My own claim for RenDanHeyi is broader still than that. I believe that the defining, generic principles of the model-a network of self-organizing, self-governing, and self-motivating micro-units serviced by platforms and united in a common purpose and by common values and a common strategic vision-offer a revolutionary organizational model, per se, particularly suited to the realities of the Quantum Age.

In following chapters of this book, I will be illustrating how it suggests a new way to realize more potential in ourselves as individuals, a new way to organize and govern cities and societies, even a new way to educate our children, and perhaps the basis for a new kind of global order. I also believe that the organizing principles of the RenDanHeyi model combine the best qualities of both East (collectivism and harmony) and West (dynamic individualism), while discouraging their less beneficial extremes, thus making it a potential vehicle for greater East/West understanding and collaboration.

\section{The Model}

RenDanHeyi (roughly pronounced as "RenDanHyoy") is translated by Haier to mean "the value to the employee is aligned with the value to the user," and this emphasis on an alignment between people who are partners in a win/win relationship is critical to the deeper philosophical roots of the model. A play on the famous Taoist mantra Tian Ren Heyi, "Man aligned with Heaven," this emphasizes the model's deep commitment to alignments of various kinds, reflecting the Taoist view that when 
Man is aligned with Heaven, and then brings the power of this alignment to his projects and activities on Earth, such alignment brings maximum benefit and harmony to the whole of humanity. This basic harmonizing principle, found in all ancient China's philosophies, is the root of a thousand year old Chinese preference, still very much alive today, for win/win solutions in matters of both business and diplomacy, something I believe is not properly understood about China in the West today.

Tian Ren Heyi and its Heaven/Man/Earth Triad as an inspiration for RenDanHeyi may also explain why Zhang Ruimin himself was also drawn to look for inspiration and guidance in science, particularly quantum physics and complexity science, while conceiving his model. Taoism holds that there is one Way (the Tao) for all things in the universe, just as modern science holds that all things in the universe follow the laws of physics, although both the Tao and the laws of quantum physics themselves constantly adapt as the systems in which they operate evolve. As the subtitle of complexity scientist's Geoffrey West book, Scale, expresses it, "One law for the universe, organisms, cities, and companies." Perhaps doctors' advice to politicians during the Covid-19 pandemic to "Follow the science!" is good advice to company leaders also. The whole premise of this book is that it is, and RenDanHeyi does so.

RenDanHeyi also expresses the very Taoist and quantum insight that we live in a Zero Distance world of entanglement where everything is connected to everything and that no part of a system can thrive unless all parts of the system thrive. In this case, RenDanHeyi is saying that the employees (Ren) of a company, indeed the company itself, cannot thrive and enjoy value unless the customers/users (Dan) it serves thrive and enjoy value from (are aligned with, Heyi) their products and services. Having borrowed the term from the writings of Peter Drucker, the RenDanHeyi Model is also known as the "Zero Distance Model," as befits any Quantum Management model.

Just like Quantum Management itself, RenDanHeyi embraces a philosophy of leadership, a whole philosophy of life, and a set of values. The driving philosophical principle underpinning RenDanHeyi is a deep respect for human dignity, the autonomy of the individual, and a belief that all autonomous individuals are unique and each has the potential to create his or her own distinctive value if allowed freedom to do so. Newtonian/Taylorian companies, which treat the employee as a tool or resource of management, there to do its bidding as told, rob employees of this dignity, autonomy, and potential. This both defeats the possibility of 
employees finding meaning, joy, or a sense of purpose in work, and denies companies all that lost potential, including lost motivational potential, resulting in less innovation and lower productivity. The entire structure of RenDanHeyi is designed to implement this wider philosophical view in practice. We will look at the generic characteristics of each of its defining principles now, and see how it is that each represents quantum principles in action.

\section{BotTOM-Up Replaces TOP-DOWN}

Zhang Ruimin says that his motivation to derive a new management model was his strong belief that traditional management theories are no longer relevant today and must be reinvented. Taylorism, and Adam Smith's praise for the division of labor which it incorporates, were designed for the age of the machine, steam engines and internal combustion engines, and the more simple, atomistic, and deterministic, thus predictable, age made wealthy by that kind of technology. Machines are designed by blueprint, consist of simple, separate parts, and operate according to simple, fixed rules, just as companies and other organizations intended to function as no-surprise machines are governed by design from the top and structured according to the iron rules of bureaucracy into siloed functions enabled by workers who will do as they are told, like good machines themselves. But as we have seen, the twenty-first century is an age of uncertainty, rapid change, and interconnectivity, the age of the Internet and the Internet-of-Things (IoT) (everyday objects embedded with devices that enable them to communicate via the Internet), and this new age is enabled by quantum technology and all its associated complexity. Also, today's employees are better skilled and better educated, and have far more potential to offer their companies than serving as mere robots.

Quantum technologies such as the Internet, like the physics on which they are based, eradicate borders and boundaries with their essential interconnectedness, give rise to unplanned self-organization on which it thrives, and have infinite potential constantly to generate emergent, unpredictable disruptions. This demands a management model that is itself sufficiently flexible and adaptable to absorb uncertainty and the shocks of constant disruption and to thrive on the opportunities they offer. This is what makes Zhang Ruimin say that, "In the future, all 
management must be Quantum Management," and why RenDanHeyi is an excellent means to implementing it.

- Goodbye to Bureaucracy, Middle Management, \& Borders: Although many business leaders agree with management guru Gary Hamel's saying that bureaucracy "saps initiative, inhibits risk taking, crushes creativity, and is a tax on human achievement," " they maintain it is a necessary evil for managing large companies, and continue to embrace its stranglehold, and the monster is growing. While the number of employees in big companies has increased by only $44 \%$ in recent years, the number of middle managers has grown by $100 \%$. Most employees working in companies with a workforce of larger than 5000 are buried under eight levels of middle management. They are also assigned to fragmented, siloed functions and expected diligently to follow instructions as these filter down through the hierarchical chain of command. Power comes from the top and the employees, stifled by all that middle management and its endless rules, regulations, and forms, are treated as mindless robots. The result is not just squandered employee talent and potential, but also employee stress and boredom, low morale, lost man hours, and of course, low productivity and growth. Over the past 12-14 years, as we have just noted, the average annual growth in these bureaucratic monstrosities has been only $1.1 \%$, while, by contrast, over that same period of time, Haier's RenDanHeyi implementation has delivered $23 \%$ annual growth, with increased annual revenue of $20 \%$.

The first rule of RenDanHeyi is to get rid of all bureaucracy and clear out the middle managers. Make the organization lean and agile. The whole idea of linear management goes out the door with this, including all power coming from the top. At Haier itself, today, there are only two layers of management between the CEO and front-line employees. Next, get rid of the siloed, monopolized functions and their borders between employees and replace them with multi-functional, cooperating teams empowered to make decisions, take responsibility, draft strategies, conceive products and/or services, cooperate with each other, and communicate

${ }^{1}$ Gary Hamel, "The End of Bureaucracy," Harvard Business Review, NovemberDecember 2018, p. 52. 
directly with customers/users. After firing 12,000 middle-managers, Haier divided itself into 4000 independent "micro-enterprises," referred to as MEs. Those now unwanted middle managers were given the choice to join the new model as entrepreneurs running their own MEs, or let Haier help them find jobs elsewhere. But countering that original loss of so many jobs, the RenDanHeyi transformation has since created tens of thousands of new jobs.

- Self-Organized, Self-Motivated, Self-Rewarding: In quantum systems, any kind of outside influence or intervention "collapses the wave function," i.e., eliminates potentiality. In complex adaptive systems (living quantum systems, including human bodies and human social systems), outside intervention or top-down control destroys the interconnectedness/holism and creativity of the system, eliminating natural evolution (growth) and limiting sustainability. Thus in RenDanHeyi, bosses do not assign people to the independent teams, or micro-enterprises (MEs), do not tell teams what or how to do, do not dictate how teams are composed, or give them fixed goals they must achieve. Instead, the teams are self-organized and self-selecting and work toward more long-term, all-embracing targets.

At Haier, each micro-enterprise has the "Three Rights" normally kept by senior management in a hierarchical company: (1) the right to set its own strategy, decide its own priorities, how to achieve its targets, and what partnerships it wants to make; (2) the right to hire its own employees, assign them their roles, and decide on cooperative relationships; (3) the right to set the pay rates of each team member and how to distribute bonuses among them. As is the case with sub-atomic particles within the atom, each member of an $\mathrm{ME}$ team is able to change their identity (role/function) to stand-in-for or replace another when challenges or opportunities facing the team system require this. Indeed, even MEs can come and go, as some fail and new opportunities arise.

At Haier itself, which has a company purpose to make everyone an entrepreneur and to give each employee the opportunity to achieve his or her full potential, each of these self-organizing microenterprises is a small independent company in its own right, with its own CEO, offering its own products and services, owned by its members, creating and communicating with its own customers, motivated both by a wish to see their company succeed and, thus, to bring value to their customers/users, and rewarded both by a sense 
of personal achievement and by their ability to keep most of their own company profit and share it among themselves as they choose. Most employees at Haier are paid directly by their customers rather than by receiving salaries from the company. At Roche Pharma India (Chapter 18), the independent, self-organizing sales teams found reward in the greatly enhanced sense of meaning and purpose their jobs now had, and in their personal ability to decide and design the services they could offer to doctors and their patients.

Again, at Haier, there are three types of MEs/micro-enterprises: (1) market-facing MEs that deal directly with users wanting the company's range of traditional appliances, though constantly transforming these products in dialogue with changing customer needs and newly available technology; (2) "incubating MEs" that are constantly extending exploring new business opportunities and extending Haier's product and service lines into new areas such as e-gaming, biotechnology, health care, etc., and (3) node MEs that supply component parts, or services like marketing or human resources to the market-facing ME's. Others connect traditional Haier appliance products like smart refrigerators or smart wine coolers to other companies offering food or wine products so that these commodities can be delivered to users in rapid time. These kinds of collaborative activities, and even partnerships based on "temporary contracts" with other companies have now been hugely extended with Haier's recent move into offering its users "scenarios" and "Eco-System Brands," which I will discuss below.

Generically, I believe the RenDanHeyi model of small, independent, self-organizing micro-entities or teams can be adapted to how community services can be offered in cities, to how both local and national health services can be provided, to how national and global infrastructure projects can be organized, and to how learning opportunities in schools and universities could be hugely broadened and kept both up to date and relevant to students' differing interests. We will explore some of this in later chapters.

- Independent But Aligned: On the surface, dividing a company or any other organization into thousands of independent, self-organizing entities might sound like a recipe for fragmentation and anarchy. But the RenDanHeyi model makes Haier a coherent, well-coordinated organization that ensures cooperation and alignment between all 4000 of its operating micro-entities. A strong, central operational 
system was designed for the entire conglomerate as a first priority. Senior management ensures a company culture that sets common standards and values, common operating procedures, and kpis (key performance indicators) for every ME and its members, and delivers an ever-evolving common strategic direction for the company as a whole. A network of service platforms, each also independent and owned by the platform entrepreneur, and each bringing together more than 50 MEs, act as facilitators for coordinating cooperation between the differing MEs, arranging collaborative discussions, and making them aware of joint entrepreneurial opportunities.

Platform owners thus serve the MEs with such facilitation, and also provide the wider service benefits, including start-up resources when needed, of a large company to the much smaller MEs, which then function more like start-ups. They guide and facilitate, but never command. But platform owners are also entrepreneurs in their own right, selling their services to the company's vast internal market, having their own growth targets, and the responsibility of looking for ever more opportunities to create new MEs.

Another level of system coordination is provided by "integration nodes" that exist within each platform. These ensure an integrated supply of component parts from all manufacturing MEs in the company, provide new competence skills to MEs about such things as smart manufacturing and big data marketing information, administrative services, etc.

These central coordinating structures provide the always necessary, Newtonian "particle aspect" of any quantum organization, while the self-organizing independence of the individual MEs provides the "wave aspect"-thus giving RenDanHeyi the dual benefit of any quantum system's both/and, wave/particle duality.

- The Customer/User Is Now the Boss. RenDanHeyi insists that the core competency that any organization must have is an ability to create value for its customers/users. Organizational purpose and success begin and end with a continuing ability to meet ever-evolving user needs. Thus the model requires Zero Distance between the employees who make, sell, and service products and the users who buy them. "Employees must know their users better than they know themselves," says Zhang Ruimin, and this in turn requires a constant, co-creative dialogue between them via every means 
available-telephone, internet surveys and conversations, user feedback mechanisms, face-to-face meetings, and even home visits where relevant. The user should always feel the employee is "at his/her service," contactable, and interested.

RenDanHeyi assumes that users are partners of the organization, sometimes even becoming employees themselves, whose feedback and suggestions inspire new product and service developments, thus stoking the fires of innovation. Some adaptations of the model, such as Haier's own, allow for users to share the profit or advantages of a suggested new product or service, themselves becoming user-entrepreneurs. This is an implementation of the co-creative quantum relationship between the observer and the observed which tells us that in observing and questioning reality, relating to reality's potential, we make reality "happen," we turn the possible into the actual. Through observing, discussing, and relating to user needs and suggestions, the employee and the user together cocreate innovative realities.

- Relationships Make the Organization: We have seen that our quantum universe is literally made of relationships, and thus it is relationships that make reality. There are even "particles of relationship," called bosons, described by quantum physics as the "glue" that holds everything together. All four of the Fundamental Forces-gravity, electro-magnetism, the strong and weak nuclear forces-are made out of bosons, and in a proper understanding of how the universe works, the word "force" itself must really be understood as "the presence of a relationship." And built into the term RenDanHeyi itself, too, is this understanding of a fundamental, defining relationship between the employee and the customer/user similar to the role feedback loops play in cybernetic theory. Thus any company or organization implementing the RenDanHeyi management model sees that its fundamental organizing principle must be the building of Zero Distance relationships.

In the big e-commerce companies like Amazon and Alibaba, multiple independent companies are serviced by common eplatforms, but there is no relationship between the various companies served, and each has only transactional relationships with its own customers. We have seen that RenDanHeyi makes an "up close and personal" relationship between the micro-enterprises and their users a first priority, but it also mandates cultivating cooperative, 
co-creative Zero Distance relationships between all the company's micro-enterprises. At the very least, there should be shared knowledge throughout the networked system of what others are doing. There must be opportunities for cross micro-enterprise discussions and a sharing of ideas to cross-fertilize innovation throughout the system. There must be a cultural sense of belonging together for the shared purpose of creating value, for the user, for themselves, for each other, for the company as a whole, and for all the other players in the company's system of relationships-share-holders, the community, the planet, etc.

- Open Innovation: Most companies and other organizations are very secretive about their research for innovation. Innovative ideas are seen as company capital, and everything is done to stop possible competitors "stealing" it. But RenDanHeyi, which sees the value of all relationships, calls for building a strong, co-creative relationship between company "insiders" and those "outsiders" in the surrounding environment. So Haier, for instance, does not just build Zero Distance relationships with its users to mine their needs and thoughts for innovative ideas, but instead goes much further in seeking the creative help of the entire outside community.

Both known problems facing company $\mathrm{R} \& \mathrm{D}$, as well as appeals for "bright ideas" about new products or product features, are posted on social media for all to see and respond to. Sometimes as many as three million people respond to such requests for creative input that relates to a given problem with an existing product or the opportunity to create a new one. The company also communicates regularly with 400,000 "solvers," both individual experts and expert research institutions as it seeks advice, feedback, and ideas that will further innovation. Those individuals or institutions whose input is used in a successful new product or service are then rewarded with a share in any profit that will be realized. Some even join the company as heads of new ME's.

This "no borders" approach to innovation and creativity means that RenDanHeyi sees every citizen as a fellow partner or fellow entrepreneur, thus implementing the quantum principle that, because everything in our universe is entangled, because everything and everyone is part of everything and everyone else, there are no "outsiders," there are no "strangers." We are all part of one, larger, cooperative, and co-creative system. Gary Hamel observes that by 
putting its product development process online and thus open to all, "Haier has reduced the time from concept to market by up to $70 \%$." 2 Imagine the benefits to global health if all the many institutions in the world's many countries that were seeking to discover and then to manufacture a vaccine for Covid-19 had followed the RenDanHeyi model!!

- From Fear to Experiment and Innovation: Psychological studies have shown that fear is the central motivation driving employees in large, bureaucratic companies and other organizations. A fear of making mistakes. A fear of upsetting the boss. A fear of rocking the boat. A fear of being fired. Thus most established companies follow the motto, "If it works, don't fix it." But this makes them essentially conservative and risk-averse, and risk aversion stifles innovation. Our quantum universe as a whole, and the living organisms within in it that we call complex adaptive systems, take risks all the time. They thrive on risks because the creative function of risks is built into their nature. Risks are experiments, risks are recce missions into the Future, they are the key to evolution and growth. And being itself a quantum model in practice, RenDanHeyi creates a system structure that accepts and thrives on risk.

Each RenDanHeyi micro-entity, because there are so many of them, is free to be an exploratory "finger into the future," behaving like one of the multiple "virtual transitions" that an atomic system throws out in preparation for a move to a different energy state. Each such virtual transition explores one possible path to the future state, and even if this is not ultimately the path the system will take, the virtual transition nonetheless has real effects in the real world as it conducts its trial run. Similarly, each of Haier's many ME projects may or may not succeed in the marketplace. If they do not, they are allowed to fail, without the larger company system suffering any significant consequences. But the failed experiment itself enriches the total system with the experience and knowledge gained through the experiment, and thus was worthwhile. Haier always gains from experimentation, while celebrating diversity and even thriving from any adversity that arises.

2 Ibid., p. 57. 
- Ecosystems: A Superposition of Possibilities. We have seen that the quantum universe is a system of systems. Even each individual quantum wave function is a system of superimposed possibilities, each a rich new reality waiting to happen. And these new realities come about as elements of the system form new relationships. RenDanHeyi's employment of ecosystem alliances gives a quantum company this same almost infinite potential to branch out by turning possibilities into new, combined realities in every direction. Many possibilities for many different ecosystem alliances and thus new opportunities are created with each new relationship. This gives a quantum organization the possibility of constant, endless growth, and even perhaps "eternal life."

When Haier first introduced RenDanHeyi by dividing the company up into thousands of smaller micro-enterprises, it found that a kind of dog-eat-dog, zero-sum competition emerged between them. Each thought only of its own possible success. So very soon into the company's transformation, an ecosystem model of win/win cooperation was encouraged. It was quickly noticed that users very seldom came shopping for just one appliance, but rather that someone who purchased a new toaster would soon after, and perhaps simultaneously, order a new microwave and/or a new iron. Similarly, within Haier's own internal market, a market-facing ME needing a component part from one manufacturing ME also needed another from a second, and so on. MEs quickly learned that if they teamed up to form temporary partnerships, they could offer more "total solutions" to users, saving the users searching and shopping time and benefiting themselves from a combined market. Today, Haier is a network of cooperating ME's, sometimes as many as 400 at a time, forming temporary alliances to give users these desired total solutions. As in quantum holism itself, the whole (shared profit derived from the larger market) is greater than the sum of the parts (sold individually, one at a time).

In 2019, Haier went even further with developing the ecosystem idea by introducing its new Eco-System Brand. Discovering as it went along that users liked buying its own products in combinations that would fill a multiplicity of needs, the company began offering whole "scenarios," such as its "balcony scenario." Originally thinking that people would use their balconies as a place to locate their washing machines, they soon discovered users would like to 
add a sofa, perhaps a mini sound system, even a piece or two of sporting equipment. The idea for the "balcony scenario" evolved from this, but that required reaching out to other companies, like the sporting goods company Decathlon, with the offer of a temporary contract to supply any such items as part of the new balcony scenario "product," and the whole combination was offered as an Eco-System Brand. The partnering companies negotiate a temporary contract through which each partner makes some profit from every item included in the scenario package (see more in Chapter 17). Now the borders fell, not just between individual functions and ME's within Haier, but between Haier and other companies. Haier now sees itself more as the "hub" of a vast multi-company network than as a mere "company," and the scenarios/Eco-System Brand benefit is key to its long-standing preference to aim for growing numbers of loyal customer numbers rather than concentrating on market share as a criterion of success. As Zhang Ruimin sums up this logic, "By fulfilling users every need, we are cultivating life-long users that will stay with us."

As in the quantum universe, with RenDanHeyi, everything is connected to everything and the whole system gains from a network of win/win solutions. In (Chapter 2), we looked at the quantum concept of "emergence," through which an entirely new reality arises from a relationship of constituent parts. We can now say that a quantum company like Haier "emerges" out of the relationships within its ecosystem. Indeed, each individual enterprise, through its relationships to the others in RenDanHeyi, acquires new, emergent possibilities. All both sustain themselves and grow at the same time. Now functioning like living organisms, they become "living companies." I will imagine this happening between nations on a global scale in (Chapter 22).

\section{A Different Kind of Leadership}

The Newtonian/Taylorian CEO or other leader is a powerful figure who has all the answers and calls all the shots, and he/she leads the organization from the top. But such power goes with the now-mistaken Newtonian understanding of force, something that works on people and events, something that can manipulate and control them. There are more questions than answers in today's world, and no one person can know all 
the answers and call all the shots amidst the complexity and disruptions that accompany the exponential technological changes and chaotic events we all experience now. A quantum/RenDanHeyi organization is designed to thrive on chaos, uncertainty, and rapid change, but to do so, it turns the familiar Taylorian pyramid of power on its head. Instead of the leader and senior management at the top, and employees at the bottom, the inverted RenDanHeyi pyramid puts employees at the top and management at the bottom. The leader gives up all power and instead assumes a role of service, offering support, resources, vision, and inspiration to those whom he/she leads. As Lao-tzu says in the Tao te Ching,

The best soldier is not soldierly;

The best fighter is not ferocious;

The best conqueror does not take part in war;

The best employer of men keeps himself below them. ${ }^{3}$

A complex system has many events happening all at once, and often these are disruptive. In today's complex market, there is a plethora of constantly changing or evolving user needs, in turn influenced by emerging technologies, socio/political events and, as we have just experienced, occasional global pandemics. There will be more as the challenges of climate change emerge. It takes "many hands on deck," with those hands at a Zero Distance from user needs, supply chains, and potential partners with whom necessary alliances can be made to keep up with all this complexity, and those many hands must have the power to make quick, local decisions and alliances as necessary. It was precisely because Haier had the very agile RenDanHeyi structure, with its 4000 MEs and their ability to form spontaneous alliances quickly, in place, that it could be one of the very few big retail companies to thrive during the Covid19 crisis. But it needs a very special kind of leader, a quantum leader, to guide such a complex network of independent, self-organizing entities.

All human groups and organizations need leaders. People do look to leaders who can keep the "tribe" or the "ship" steady and who can provide a compass they can follow, both morally and in practice. But the RenDanHeyi leader sees power as a supportive relationship and an ability to be related to. He/she listens, heeds suggestions, alternative views, and constructive criticism. Such leaders lead with their persons, with their

3 Tao te Ching, No. 68. 
example, with their clearly expressed ability to "walk the talk," and have cultivated power within rather than power over. They have faith in the potential of those whom they lead. They trust their employees or citizens, and of equal importance, these employees or citizens know they can trust them.

Leaders are often referred to as "the captain of the ship," but we have seen that the RenDanHeyi organization is a fleet with many ships, each with its own captain and crew and its own, local mission to accomplish. So the RenDanHeyi leader is more like the "admiral of the fleet" who provides an overall strategic vision, a "central operational system," services and resources for the many ships in the fleet, and a guiding spirit that inspires, motivates, and maintains a harmonious coherence among all the many crews as each self-organizes its own mission and alliances-and does all this as with "an invisible hand," exercising force not on people but, rather, through people. He/she serves the fleet and its crews rather than controlling them, and sees him/herself as a Servant Leader.

The whole of Part III of this book is about the nature, challenges, and strategic and creative thinking of the quantum leader, and the whole of Part IV is more about the nature of the quantum organization, with case studies of several companies that have implemented Quantum Management thru the various adaptive possibilities inherent in RenDanHeyi. But first I think we need a still deeper understanding of the philosophical roots and vision of the quantum/RenDanHeyi model and how these release deeper potential for each of us as individuals, whether we serve our organizations as employees or as leaders. 
Open Access This chapter is licensed under the terms of the Creative Commons Attribution-NonCommercial-NoDerivatives 4.0 International License (http:// creativecommons.org/licenses/by-nc-nd/4.0/), which permits any noncommercial use, sharing, distribution and reproduction in any medium or format, as long as you give appropriate credit to the original author(s) and the source, provide a link to the Creative Commons license and indicate if you modified the licensed material. You do not have permission under this license to share adapted material derived from this chapter or parts of it.

The images or other third party material in this chapter are included in the chapter's Creative Commons license, unless indicated otherwise in a credit line to the material. If material is not included in the chapter's Creative Commons license and your intended use is not permitted by statutory regulation or exceeds the permitted use, you will need to obtain permission directly from the copyright holder.

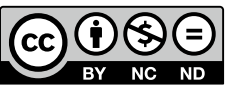

